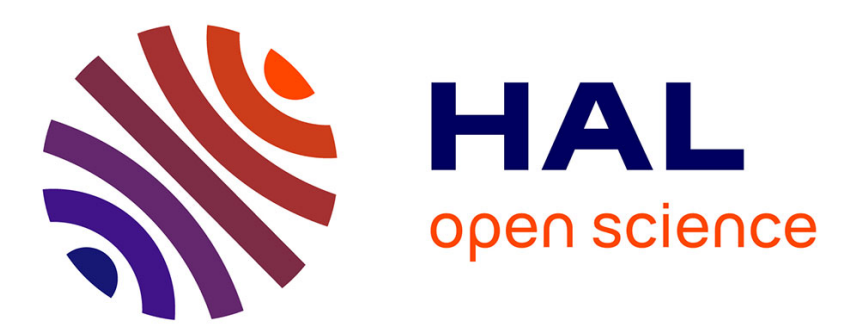

\title{
Bathing beauties, bodybuilders et surfeurs : l'émergence de cultures corporelles originales sur les plages de Los Angeles (années 1920-1930)
}

Elsa Devienne

\section{- To cite this version:}

Elsa Devienne. Bathing beauties, bodybuilders et surfeurs : l'émergence de cultures corporelles originales sur les plages de Los Angeles (années 1920-1930). Revue Française d'Etudes Américaines, 2015, 142 (1), pp.24. 10.3917/rfea.142.0024 . hal-01640460

\section{HAL Id: hal-01640460 \\ https://hal.parisnanterre.fr/hal-01640460}

Submitted on 4 Dec 2017

HAL is a multi-disciplinary open access archive for the deposit and dissemination of scientific research documents, whether they are published or not. The documents may come from teaching and research institutions in France or abroad, or from public or private research centers.
L'archive ouverte pluridisciplinaire $\mathbf{H A L}$, est destinée au dépôt et à la diffusion de documents scientifiques de niveau recherche, publiés ou non, émanant des établissements d'enseignement et de recherche français ou étrangers, des laboratoires publics ou privés. 


\title{
Bathing beauties, bodybuilders et surfeurs: l'émergence de cultures corporelles originales sur les plages deLos Angeles (années 1920-1930)
}

Elsa Devienne

\begin{abstract}
Fascination with Los Angeles's beaches and their bodies started long before the series Baywatch. While the iconic figures of the pin-up, the body-builder, and the surfer may seem to be the products of the prosperous postwar period, they are actually rooted in much older bodily practices. These cultures of the body emerged on the city's beaches at the beginning of the century and flourished in the 1920s and 1930s, when Los Angeles reached one million residents and emerged as one of the great metropolises of the American West. This article traces the emergence of these icons-both on the city's beaches and in popular culture-and analyzes their role in the making of a specific beach culture in Southern California.
\end{abstract}

Les références à la plage sud-californienne sont omniprésentes dans les imaginaires contemporains de l'univers balnéaire: le surfeur aux cheveux blondis par le soleil, le sauveteur en mer bronzé, la starlette en maillot de bain et le sportif bodybuildé sont des figures emblématiques qui colorent notre expérience de la plage, que l'on soit à Malibu ou sur les rivages normands. Diffusées à travers le monde par le biais du cinéma, de la télévision, des journaux et de la publicité, ces «corps de plage» ont acquis le statut d'icônes, au point qu'ils sont aujourd'hui déconnectés de leur contexte d'émergence. De surcroît, et en dépit de leur succès planétaire et du caractère quasi universel des normes de beauté qu'ils ont contribuées à diffuser, leur histoire demeure relativement mal connue. Les spécialistes du surf, du corps et de la beauté et, 
plus ponctuellement, les historiens de la Californie, se sont interrogés sur le succès de ces icônes et des pratiques qui leur sont associées, mais ces études privilégient généralement l'angle de l'histoire des représentations et délaissent une histoire sociale plus locale qui permettrait de comprendre le contexte d'émergence de ces cultures corporelles. Surtout, ces études se concentrent en général sur la seconde moitié du Xxe siècle. En effet, dans les années 1960, le surf connaît un succès fulgurant, qui touche l'ensemble des industries culturelles (musique, cinéma, vêtements, etc.), tandis que le corps californien bronzé et musclé s'impose au sommet du panthéon de la beauté moderne (May; Diamond; Booth). Ces deux phénomènes ont focalisé l'attention des historiens et ont eu tendance à éclipser la période antérieure, pourtant fondatrice en ce qui concerne la genèse de ces cultures corporelles.

En effet, contrairement à ce que l'on pourrait croire, les figures de la bathing beauty ${ }^{1}$ du bodybuilder et du surfeur ne sont pas les produits de la société prospère de l'après-guerre. Elles apparaissent sur les plages de Los Angeles dès le début du Xx $x^{\mathrm{e}}$ siècle et s'épanouissent dans les années 1920 et 1930, alors que la ville connaît une croissance démographique spectaculaire et une expansion rapide de ses quartiers littoraux. L'enjeu de cet article est de redonner à ces figures emblématiques leur épaisseur historique et, en particulier, de souligner le lien entre leur émergence et la transformation de Los Angeles au début du $\mathrm{Xx}^{\mathrm{e}}$ siècle en grande métropole de l'Ouest américain. Dans cette ville d'un nouveau genre, où la maison individuelle avec jardin domine le paysage et où les parcs publics sont rares, les plages deviennent des espaces publics clés. À l'instar de Central Park à New York, le rivage de Los Angeles constitue un lieu de rencontre, où les habitants de la ville croisent des personnes de classes sociales et d'origines ethniques diverses, à l'exception des Africains-Américains, qui sont cantonnés à certaines zones de la baie et se voient refuser l'entrée aux plages les plus prisées ${ }^{2}$. Vastes et éloignées du regard des autorités - les premières équipes

1. Il s'agit d'un terme difficilement traduisible en français, qui désigne les jeunes femmes qui posent en maillot de bain pour les peintres et les photographes, et dont l'image est utilisée dès le $\mathrm{XIX}^{\mathrm{e}}$ siècle pour faire la publicité des stations balnéaires. Le type de la bathing beauty est ensuite adopté dans les années 1910 et 1920 par les cinéastes de Hollywood, qui en font un archétype féminin connu de tous et déployé sur tous les supports visuels.

2. Les plages de Los Angeles font l'objet d'une ségrégation raciale pendant toute la première partie du siècle. En 1927, un swim-in organisé à Manhattan Beach par la branche locale de la NAACP (National Association for the Advancement of Colored People) donne lieu à un procès qui met fin à la ségrégation officielle des plages de la région. Toutefois, des pratiques ségrégationnistes informelles se maintiennent. Les Africains-Américains sont cantonnés aux plages de l'Inkwell (au sud de Santa Monica) et de Manhattan Beach. Ceux qui s'aventurent sur d'autres rivages font face à des insultes, voire à des violences physiques. Sur cette question, voir Alison Rose Jefferson, «African-American Leisure Space in Santa Monica». Southern California Quarterly 91.2 (2009): 155-189; Douglas Flamming, Bound for Freedom: Black Los Angeles in Jim Crow America (Berkeley: University of California Press, 2006) 272-275. 
municipales de sauveteurs en mer sont créées dans les années 1920 (Verge 2005, 24), mais ces derniers n'ont pas le droit de procéder à des arrestations et la police ne se déplace que rarement sur le sable - elles constituent des lieux privilégiés d'expression corporelle, où il est possible de laisser de côté les conventions sociales et les normes vestimentaires qui régissent les corps en ville. En d'autres termes, sur le sable, les corps - tout du moins les corps blancs - jouissent d'une plus grande liberté que sur le macadam.

Toutefois, les plages demeurent fondamentalement des espaces urbains: l'objectif de cet article est en effet de montrer que c'est sous l'influence de la ville, de ses habitants, de ses institutions culturelles et de ses centres de décision économiques que ces formes d'expressions corporelles originales se développent sur le littoral. Il s'agira de mettre en avant trois influences en particulier: l'installation et le développement de l'industrie du cinéma dans la région métropolitaine; l'émergence d'une sous-culture du sport spécifique à Los Angeles; la proximité physique et culturelle d'Hawaï et l'apparition du surf sur les côtes californiennes. Ces trois phénomènes sont étroitement liés au développement de la ville: Hollywood est d'abord un quartier de Los Angeles avant d'être une industrie; le sport gagne ses premiers adeptes dans les clubs privés du centre-ville et le surf est importé en parallèle à la mise en tourisme de la côte. Le contexte urbain est donc crucial dans la formation d'usages et de cultures de plage spécifiques. À l'intersection de ces trois domaines d'influences, les cultures corporelles qui émergent sur les plages de Los Angeles se distinguent de plusieurs manières. Tout d'abord, elles s'intègrent très tôt à un mode de vie centré sur le sport en plein air et le loisir, caractéristique de la Californie du Sud et de la douceur de son climat. Ensuite, les sports pratiqués sur la plage n'ont pas une visée simplement hygiéniste ou éducative: dès les années 1920, il s'agit d'une activité entreprise, d'abord et avant tout, pour le plaisir ou dans le but d'embellir son corps. Enfin, ces activités mêlent à la fois le sport, le jeu, la fête et le spectacle. Ces différentes caractéristiques contribuent à la définition d'un modèle balnéaire proprement sud-californien, qui se distingue des modèles plus anciens, venus de la côte Est ou d'Europe ${ }^{3}$, et s'impose rapidement dans le panorama mondial des cultures de plage.

\section{L'influence de Hollywood}

Si les historiens se sont penchés sur les liens qui se tissent entre les cultures de plage sud-californiennes et Hollywood dans l'après-guerre, en

3. Les stations balnéaires fondées sur la côte de Los Angeles au tournant du $\mathrm{Xx}^{\mathrm{e}}$ siècle s'inspirent largement du modèle de Coney Island et d'Atlantic City sur la côte Est. Venice est ainsi qualifiée de «Coney Island de l'Ouest» dans les brochures publicitaires. La Riviera méditerranéenne est une autre source d'inspiration, en particulier pour les stations balnéaires ou les projets immobiliers littoraux qui cherchent à attirer une population plus aisée. 
particulier dans les années 1960 au cours desquelles les studios produisent une vingtaine de beach movies, ces films destinés au marché adolescent qui mettent en scène des surfeurs et des starlettes en bikini ${ }^{4}$, les antécédents de cette relation n'ont pas été mis au jour. Pourtant, dès l'arrivée de l'industrie cinématographique en Californie à la fin des années 1900, l'océan et les plages occupent une place importante, aussi bien dans les productions filmiques que dans le mode de vie des membres de la «colonie du cinéma» (Starr 334). Tout d'abord, les plages sont un lieu de tournage de prédilection: vastes, souvent vides l'hiver, elles sont l'endroit idéal pour tourner des scènes de poursuite, élément essentiel de ce nouveau genre comique qui se développe alors, le «California Slapstick ${ }^{5}$ ». De nombreux studios sont ainsi fondés dans les quartiers littoraux et tirent parti de cette proximité. Même les studios Keystone de Mack Sennett, situés à Edendale, à l'est de la ville, tournent régulièrement sur les plages. La lecture d'un journal local comme le Palisades Del Rey Press rend compte de cette frénésie d'activité filmique sur le sable. En l'espace de deux ans, de 1926 à 1928, quatre tournages ont lieu sur les plages de Del Rey, qui deviennent, en fonction des besoins du script, les rivages de la Riviera ou les dunes du Sahara ${ }^{6}$.

D'autre part, la plage s'impose rapidement comme un lieu de vie des stars du cinéma, que ce soit sur la «Gold Coast», le long de Santa Monica, ou encore à Malibu. À Santa Monica, les premiers à faire construire des maisons sur le sable sont des grands noms de Hollywood comme Louis B. Mayer, Jesse Lasky, Douglas Fairbanks et Mary Pickford. Celle de l'actrice Marion Davies, construite entre 1926 et 1930 par son amant William Randolph Hearst, comprend une piscine, un terrain de tennis et pas moins de 118 chambres. S'installer à la plage, ce qui est encore inhabituel au début des années 1920, devient rapidement un symbole de distinction, voire une stratégie publicitaire afin d'établir une image de marque, à l'heure où les grandes stars hollywoodiennes doivent se distinguer les unes des autres. Surtout, la plage devient alors le lieu par excellence où les corps sont révélés et les

4. Les historiens du cinéma s'accordent pour dire que le cycle des beach movies commence en 1959 avec l'immense succès au box-office de Gidget (1959), film adapté du roman du même nom, et s'achève en 1965 avec les derniers films du genre. Les plus connus sont les sept films tournés par les studios American International Pictures (AIP), dont le premier, Beach Party (1963), met en place les ingrédients indispensables du genre: une plage californienne déserte, une bande de jeunes gens blancs en maillots de bain et équipés de planches de surf, un groupe d'intrus contre lequel le groupe doit se défendre (notamment les blousons noirs), sans oublier une bande originale composée par les groupes de surf music les plus en vogue (May, 117-134).

5. Le slapstick est un genre filmique qui se développe dans les années 1910 et 1920 et qui est caractérisé par un humour dit physique car centré sur les corps. En français, on traduit cette expression par «comédie burlesque» ou «comique tarte à la crème».

6. Palisades Del Rey Press, 15 août 1927, p. 8. 
comportements relâchés. Associer son image à l'imaginaire balnéaire confère ainsi aux acteurs une certaine sensualité, source d'une plus grande popularité.

Ce phénomène contribue à la popularité des plages auprès des habitants de Los Angeles, «les Angelinos», mais elle a aussi des conséquences directes sur les usages et les imaginaires du littoral qui se développent alors. L'exemple le plus manifeste est l'émergence des bathing beauties, ces jeunes et jolies femmes qui batifolent en maillots de bain dans les comédies de Mack Sennett, le maître de la comédie burlesque, entre 1915 et 1929 (D’hayere 207). Leur succès est tel que la bathing beauty devient un type d'actrice spécifique qui possède sa propre section dans les annonces d'offres d'emploi de Hollywood (Addison 38). L'émergence de ce type est à replacer dans le contexte du succès des stations balnéaires et de la mode des concours de beauté (Banner 249-261). Surtout, il est rendu possible par l'existence d'un discours sur «la nouvelle femme» (the New Woman), ce nouveau modèle féminin d'épanouissement personnel incarné, dans les années 1920, par le nombre croissant de jeunes femmes blanches salariées qui participent pleinement aux plaisirs urbains de la nouvelle culture de masse (parcs d'attractions, cinéma, etc. ${ }^{7}$. La «nouvelle femme» représente une rupture avec l'idéal féminin victorien de retenue et de pudeur qui prévalait jusque-là. Dans ce contexte, la représentation picturale de femmes jouant avec les nouveaux codes de la sensualité, de la séduction et de la coquetterie, se banalise. La spécificité de ce phénomène dans le cadre de Los Angeles tient au fait que, contrairement à d'autres endroits aux États-Unis où elles demeurent des créatures imaginaires, les bathing beauties investissent les rues et les plages de Los Angeles à la fois sur les écrans et dans la réalité. En effet, il n'est pas rare que des photographies des tournages de Mack Sennett paraissent dans la presse locale. Par ailleurs, les bathing beauties font des apparitions dans la ville lors d'événements festifs. Par exemple, en mai 1919, lorsqu'un film des studios Mack Sennett est diffusé au cinéma d'Ocean Park, les bathing

7. Le terme de «nouvelle femme» apparaît à la fin du XIX⿸e siècle et désigne une réalité sociologique en même temps qu'un concept culturel au sujet duquel les contemporains débattent. La «nouvelle femme» de la fin du XIX ${ }^{\mathrm{e}}$ siècle est une jeune femme éduquée, issue de la bourgeoisie, qui refuse le mariage et la maternité pour mener une carrière professionnelle ou s'engager en faveur de réformes sociales et politiques. Le terme évolue dans les années 1920 pour s'appliquer aux classes ouvrières et aux employées. Sur ce terme et les femmes qui incarnent ce nouveau modèle, voir Carroll Smith-Rosenberg, «The New Woman as Androgyne: Social Disorder and Gender Crisis, 1870-1936», Disorderly Conduct: Visions of Gender in Victorian America (New York: Oxford U P, 1986), 245-296; Lois Rudnick, «The New Woman», Adele Heller et Lois Rudnick, eds., 1915, the Cultural Moment: The New Politics, the New Woman, the New Psychology, the New Art, and the New Theatre in America (New Brunswick, NJ: Rutgers U P, 1991), 68-91; Estelle Freedoman, «The New Woman», Journal of American History 61 (1974): 372-393; Kathy Peiss, Cheap Amusements, Working Women and Leisure in Turn of the Century New York (Philadelphia: Temple U P, 1986). 
beauties «en personne viennent folâtrer mélodieusement à chaque séance ${ }^{8}$ ». Sennett envoie également régulièrement certaines de ses actrices pour participer à des concours de beauté locaux, comme le défilé annuel de jeunes filles en maillots de bain de Venice (D'hayere 244).

C'est ce jeu d'aller-retour entre fiction et réalité et, plus précisément, entre un espace (celui du film) dans lequel davantage de libertés peuvent être prises, et un autre (celui de la plage) où ces libertés peuvent être reproduites et, progressivement, conquises, qui accentue l'emprise de ce phénomène sur les plages sud-californiennes. Il est difficile de dire dans quelle mesure ce mouvement a pu influencer l'accoutrement des baigneurs. Il est néanmoins incontestable qu'il a durablement marqué la représentation que Los Angeles se faisait d'elle-même et de ses plages. Les publicités diffusées par la Chambre de commerce de la ville dans les années 1930 sont, par exemple, directement inspirées des bathing beauties. Elles mettent en scène des groupes de jeunes femmes en maillot de bain ou en tenues sportives sur la plage, prenant part à des activités sportives et ludiques. L'imaginaire de la plage à Los Angeles est donc, dès les années 1920, associé aux femmes, à la beauté et à la spectacularisation des corps, plus que n'importe où ailleurs.

L'influence de Hollywood sur la représentation et la définition de la beauté est renforcée au niveau local par les concours de beauté qui font constamment référence à l'univers du cinéma. En 1916, à Venice, un grand concours de cet ordre est organisé pour lequel «les différents studios ont tous inscrit leurs plus jolies filles ${ }^{9} »$. En 1928, cette même compétition compte désormais plusieurs catégories, dont celle du «plus beau figurant de cinéma ${ }^{10}$ », signe que les critères de beauté hollywoodiens s'imposent également sur les corps masculins. Par ailleurs, les journaux locaux soulignent le fait que ces événements peuvent être l'occasion de percer dans le monde du cinéma. Dans certains cas, celui ou celle qui remporte le titre peut espérer gagner un «bout d'essai à Hollywood ${ }^{11}$ ». Ce phénomène n'est pas circonscrit à la population blanche. En 1925, le Pacific Beach Club, un club de plage créé par des hommes d'affaires africains-américains afin de permettre à la communauté noire de profiter de l'océan, organise un concours de beauté en maillot de bain filmé par des caméras, «une attraction supplémentaire pour les jeunes filles qui aspirent à devenir actrice ${ }^{12} »$. Une semaine plus tard, les scènes filmées lors de cet événement sont projetées dans un cinéma du

\footnotetext{
8. Evening Outlook, 24 mai 1919, 4.

9. Los Angeles Times, 4 mai 1916, III2.

10. Evening Outlook, 23 mai 1928, 2.

11. Evening Outlook, 22 juin 1936, 1.

12. California Eagle, 28 août 1925, 1.
} 
quartier noir de South Central, le Rosebud Theater, faisant des candidates de véritables stars du cinéma, du moins le temps d'une projection. Ce lien soutenu et quotidien entre la plage et Hollywood influence les critères de beauté et fait de la plage le lieu par excellence de représentation et de mise en scène du corps.

Mais ces corps, pour être dignes de la caméra, doivent être minces, sportifs et musclés. Depuis la fin du XIX ${ }^{\mathrm{e}}$ siècle et dans le sillage du mouvement de la «muscular christianity», qui fait l'apologie de la vigueur physique comme fondement essentiel de la moralité chrétienne, les activités sportives ont un grand succès aux États-Unis ${ }^{13}$. En parallèle, le regard sur les corps évolue. Si avoir un embonpoint est un signe de prospérité et de richesse au XIX $\mathrm{X}^{\mathrm{e}}$ siècle, la graisse fait l'objet de multiples attaques à partir du début du $\mathrm{Xx}^{\mathrm{e}}$ siècle, en lien avec la montée du consumérisme et d'une idéologie du contrôle de soi ${ }^{14}$. Dans les années 1920, la minceur s'impose comme l'un des attraits essentiels que doit posséder la femme et, dans une moindre mesure, l'homme. Les stars de Hollywood sont les premières à s'emparer du sport comme un outil de contrôle sur leur corps. Par le biais des magazines de fans qui se multiplient dans les années 1910 et 1920, les stars décrivent en détail les exercices à exécuter quotidiennement pour atteindre les critères de beauté hollywoodiens (Addison 5-6). Parallèlement, la plage s'impose comme un espace essentiel de la pratique et de la démonstration sportive. Ce sont d'ailleurs les stars de cinéma qui lancent ce mouvement. Sur une carte postale particulièrement révélatrice du lien qui existe entre Hollywood, la plage et le sport, l'actrice Marion Davies est représentée sur la plage de SantaMonica en plein élan, alors qu'elle tente de réceptionner un ballon $^{15}$. Si sa somptueuse demeure figure en arrière-plan, Davies se trouve sur la partie publique de la plage, mettant ainsi en avant son accessibilité. La bouche ouverte, le bras étiré au maximum, les cheveux laissés au vent, elle semble être prise sur le vif par le photographe, ce qui renforce l'air de simplicité et de spontanéité de la star, deux traits constitutifs de l'image de Marion Davies auprès du

13. Sur la «muscular christianity», voir Clifford Putney, Muscular Christianity: Manhood and Sports in Protestant America, 1880-1920 (Cambridge, MA: Harvard U P, 2001) 11-44; Tony Ladd et James A. Mathisen, eds., Muscular Christianity: Evangelical Protestants and the Development of American Sport (Grand Rapids, MI: Baker Books, 1999).

14. Il existe un débat sur les origines de ce culte de la minceur. Certains historiens considèrent qu'il s'impose en réaction à une société de l'abondance, tandis que d'autres affirment, au contraire, que la mode du régime est le produit d'une culture de la consommation, qui cherche à utiliser le manque de confiance en soi et les insatisfactions des consommateurs pour les pousser à acheter davantage de produits (pilules pour mincir, cours de musculation). Sur cette question, voir Peter N. Stearns, Fat History: Bodies and Beauty in the Modern West (New York: New York UP, 1997); Hillel Schwartz, Never Satisfied: A Cultural History of Diets, Fantasies, and Fat (New York: Free Press, 1986).

15. Werner von Boltenstern Postcard collection, Loyola Marimount University. 


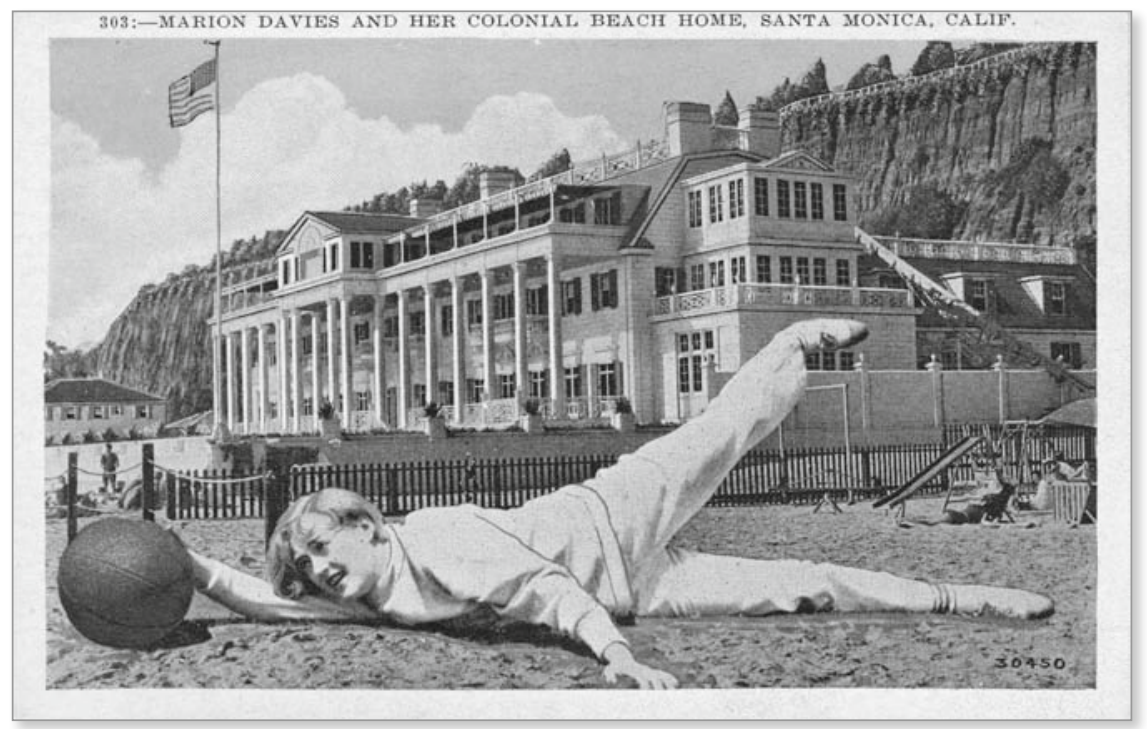

Marion Davies and her colonial beach home, Santa Monica, Calif. Werner von Boltenstern Postcard Collection. Archives and Special Collections, William H. Hannon Library, Loyola Marymount University.

public (Basinger 333). En même temps, son style vestimentaire est étudié: toute vêtue de blanc, Davies porte un ensemble sportif décontracté, qui souligne sa minceur. En donnant ainsi à voir son corps en plein effort, avec en arrière-plan sa maison et la plage, Marion Davies met en valeur les caractéristiques de son mode de vie au quotidien: sportif, chic et, en même temps, accessible à tous. Cette carte postale symbolise en effet les différents éléments qui composent la vie des stars hollywoodiennes et, progressivement, celle à laquelle peuvent aspirer de nombreux résidents de la ville, quel que soit leur statut social.

\section{L'influence du sport}

Au cours de la première moitié du $\mathrm{xx}^{\mathrm{e}}$ siècle, les plages de Los Angeles deviennent des lieux essentiels de pratiques sportives et ludiques. Ces activités s'inscrivent dans le cadre d'un mode de vie centré sur le loisir et sur la nature qui s'épanouit alors en Californie du Sud, en lien avec la croissance démographique de la région et la diffusion rapide de la voiture individuelle (Culver). Dès les années 1930, il est généralement accepté que les Californiens sont plus sportifs que les gens de l'Est. Mieux nourris grâce aux produits agricoles issus de l'irrigation intensive des sols, exposés au soleil toute l'année, les corps californiens sont perçus comme «naturellement» plus beaux et plus forts. On remarque aussi que la Californie du Sud produit un grand nombre de 
champions, en proportion à sa population (McWilliams 110). Toutefois, Los Angeles dispose de beaucoup moins de parcs que les autres grandes villes des États-Unis. Par conséquent, les activités sportives et ludiques d'envergure vont souvent se dérouler sur les plages. Les fêtes de plage (beach parties), une pratique courante à Los Angeles, donnent ainsi généralement lieu à des baignades, des jeux et des courses. Parallèlement, on adapte d'autres sports élitistes, comme le polo, le tennis et le golf, aux terrains sablonneux. Dans les années 1920, le club de natation de Santa Monica entreprend, par exemple, d'installer des filets pour pratiquer le golf sur le sable ${ }^{16}$.

Dans la première moitié du $\mathrm{Xx}^{\mathrm{e}}$ siècle, les côtes du nord-ouest de la France connaissent également un développement des activités sportives sur la plage. Les premiers clubs de plage destinés aux enfants de la bourgeoisie ouvrent dans les années 1910 et, au même moment, le gymkhana se répand sur les rivages. Après la Première Guerre mondiale, le basketball et le volley-ball sont introduits dans certains clubs de plage (Rainis, 2000 148). Mais comme l'explique l'historien Michel Rainis, quel que soit le type de sports ou d'activités pratiqués en France, «la culture corporelle de plage» «s'affirme presque essentiellement comme un moyen de développer une bonne santé» (Rainis, 2001 10). Au contraire, en Californie du Sud, l'objectif hygiéniste de l'exercice laisse très vite place à une visée ludique et hédoniste.

En effet, dans la mesure où cette culture corporelle de la plage a souvent pour cadre les fêtes de plage, elle est avant tout entreprise dans une quête de plaisir. Le mélange d'activités proprement sportives aux activités uniquement ludiques contribue à éliminer les distinctions entre le sport et le jeu, l'utile et l'agréable. Par ailleurs, les activités corporelles sur la plage sont avant tout pensées comme un moyen d'embellir son corps. Pour décrire ces dernières, le terme de «beautifying exercises» revient en effet souvent dans les journaux locaux. Par exemple, en 1928, «si vous apercevez à SantaMonica un groupe de belles femmes se courbant et se tordant dans tous les sens sur la plage», prévient le journal de la ville, «vous saurez que les femmes de la loge des Elks ${ }^{17}$ sont en plein cours de body and beauty building ${ }^{18}{ }$. L'attention précoce portée à la musculation met également en valeur le lien entre le sport et le culte du corps. Dans les années 1930, les enfants, dès l'âge d'un an et demi, comme le confirme une photographie parue dans le Hollywood Citizen News du petit Larry Sims, pratiquent l'haltérophilie afin de «préparer le concours de beauté de

16. Los Angeles Times, 2 juillet 1926, B4.

17. Il s'agit d'une association fraternelle de secours mutuel qui organise des actions charitables et dont une loge existe à Santa Monica depuis 1904.

18. Evening Outlook, 30 mai 1928, 2. 
Venice réservé aux plus jeunes ${ }^{19} \gg$. La relation entre le sport et la beauté est renforcée par les stars de Hollywood qui, à l'image de Marion Davies, se font représenter en plein effort. La mode du bronzage, qui se diffuse en Europe et aux États-Unis à partir des années $1910^{20}$, et l'habitude de porter des vêtements sportifs de couleurs claires, même quand on ne pratique pas de sport, participent également de ce lien soutenu entre pratique sportive et mise en valeur des corps (Starr 19).

Les activités corporelles pratiquées sur le sable sont donc à la fois un moyen de renforcer son corps, de l'embellir et de s'amuser. "Muscle Beach», cette zone de la plage de Santa Monica où acrobates et sportifs se retrouvent pour s'entraîner, est particulièrement représentative de cette hybridité. Le phénomène prend naissance dans les années 1930: en 1931 selon Life, en 1934 selon le journal local de Santa Monica ${ }^{21}$, une professeure de gymnastique aurait obtenu de la ville l'installation d'équipements sportifs destinés aux enfants (des anneaux, des barres parallèles et une estrade) sur le sable, juste au sud de la jetée municipale. Le lieu est ensuite progressivement pris d'assaut à la fin des années 1930 par des professionnels du cirque et du vaudeville pour qui la plage est à la fois un lieu idéal d'entraînement, un espace de rencontre et une occasion d'exercer leurs talents en public (Rose; Zinkin et Hearn). Des équipements sportifs sont progressivement ajoutés par les athlètes et, à partir de l'année 1940, on y organise régulièrement des spectacles de plage composés de démonstrations de force, d'exercices aux anneaux et d'acrobaties ${ }^{22}$. Si le phénomène prend véritablement de l'ampleur dans l'après-guerre, lorsque la plage devient le cadre des premières démonstrations publiques de bodybuilding et que le lieu prend son surnom de «Muscle Beach», il témoigne néanmoins de l'existence d'une mise en spectacle des pratiques sportives et corporelles en bord de mer dès les années 1930.

Ce phénomène n'est pas sans lien avec la pratique plus ancienne de la démonstration sportive à visée promotionnelle. Elle se développe dans les années 1900, lorsque plusieurs hommes d'affaires construisent des équipements balnéaires le long des plages de la ville. Afin d'attirer les premiers touristes, on y organise des événements festifs au cours desquels des sportifs, engagés à la journée, font des démonstrations de surf, de trapèze ou de plongeon. L'histoire de George Freeth est, par exemple, bien connue. Ce métis d'origine écossaise et

19. Album personnel, Santa Monica History Museum, photographie non datée (années 1930)

20. Sur les raisons complexes qui sont à l'origine de «l'invention» du bronzage, voir Cocks 110-123; Pascal Ory, L'invention du bronzage (Paris : Éditions Complexe, 2008).

21. Life, 5 août 1946, p. 14; Evening Outlook, 8 juillet 1950, p. 6B.

22. Evening Outlook, 24 juillet 1940, 5. 
hawaiienne est découvert à Waikiki en 1907 par Jack London, qui lui consacre aussitôt des écrits enthousiastes et contribue ainsi indirectement à la renaissance du surf, dont la pratique, pourtant traditionnelle dans la culture polynésienne des îles hawaïennes, y avait décliné au cours du XIX siècle. La même année, Freeth est embauché par Henry Huntington pour faire des démonstrations quotidiennes de surf afin de populariser la nouvelle station balnéaire de Redondo Beach (Verge 86-88). L'industriel Abbot Kinney l'engage également pour attirer les foules à Venice. Bientôt, il fait le tour des différentes stations de la côte, démontrant sa capacité à «marcher sur l'eau» à des milliers de spectateurs. Tout comme les spectacles de Muscle Beach, la démonstration sportive tient autant de la performance athlétique que du spectacle de divertissement et sert les intérêts d'investisseurs immobiliers. Elle transforme littéralement la plage en scène sur laquelle les corps sont mis à l'honneur.

\section{L'influence d'Hawaï et du surf}

Les démonstrations de George Freeth puis celles du célèbre nageur hawaïen Duke P. Kahanamoku contribuent à la diffusion de la pratique du surf en Californie du Sud. Le surf, du moins dans sa version sud-californienne des années 1920 et 1930, n'est pas un sport tout à fait comme les autres. En même temps qu'il gagne de nouveaux adeptes, un mode de vie spécifique, adapté aux exigences de la pratique du surf et qu'on appellera plus tard celui du «beach bum» (cossard de plage), apparaît sur les côtes sud-californiennes: les surfeurs ont en effet la particularité de passer le plus clair de leur temps sur la plage, à attendre la vague. Ils vivent en groupe, pratiquent le ukulélé et entretiennent une relation privilégiée avec la nature - qui se lit sur leur corps, bronzé et musclé. Cette combinaison du sport à un ensemble de pratiques annexes confirme la thèse de l'hybridité de la culture corporelle des plages de Los Angeles. Le sport n'est pas entendu comme une pratique à part, à visée uniquement éducative et hygiénique. Il est intégré au loisir, à la fête, au spectacle, et plus largement, au mode de vie des amateurs de plage.

La Californie du Sud n'est pas le seul endroit où ces démonstrations ont lieu: Duke Kahanamoku surfe également sur la côte Est, à Atlantic City, et également en Europe et en Australie (Warshaw 55). Néanmoins, la greffe ne prend nulle part ailleurs aussi bien qu'en Californie du Sud. En Australie, les nageurs viennent tout juste d'obtenir le droit de se baigner de jour sur les plages et le surf est condamné par les tenants de la morale chrétienne qui détiennent le pouvoir sur les rivages. En 1908, il est par exemple interdit de surfer à Sidney (Booth 2012, 22-24). En Californie du Sud, au contraire, l'hédonisme caractéristique des cultures corporelles de la plage se marie harmonieusement à la pratique du surf. Au début des années 1920, 
on estime qu'il y a une dizaine de surfeurs sur la côte californienne. À partir des années 1930, le nombre de pratiquants augmente considérablement pour atteindre environ 200 en 1937 (Lawler 182). En 1940, les surfeurs californiens sont environ un millier ${ }^{23}$. Néanmoins, le surf a un impact bien plus fort sur la culture californienne que ne le laisserait penser le nombre restreint de pratiquants à cette époque. C'est notamment à travers le cinéma et la photographie que la figure du surfeur et celle de la surfeuse circulent en Californie du Sud et influence les cultures corporelles locales.

Dès le début du siècle, le surf est associé à la natation et à l'émergence des sauveteurs en mer. À son arrivée en Californie, Freeth travaille en tant que sauveteur en mer pour gagner sa vie et forme toute une génération de Californiens aux techniques du sauvetage. Mais c'est Thomas Blake qui va définitivement lier le surf à la figure du sauveteur en mer. Originaire du Wisconsin, Blake se rend à Los Angeles en 1921 où il combine une activité de nageur professionnel avec un travail de sauveteur en mer dans un club de plage privé (Lynch 28). C'est au cours de cette période, au gré de ses allers et retours entre Hawaï et Los Angeles, qu'il développe un nouveau design de planche, le hollowboard, plus léger mais plus long que les planches utilisées habituellement. Blake promeut sa planche comme un instrument moderne de sauvetage en mer. Il joue ainsi un rôle important dans la diffusion du surf en écrivant des articles et des photographies dans plusieurs publications comme le National Geographic (Blake 597-604). Surtout, il publie en 1935 un ouvrage intitulé Hawaiian Surfriders afin d'expliquer l'origine et l'utilisation du hollowboard, dont il organise en parallèle la production en usine aux États-Unis (Lynch, Gault-Williams et Hoopes). Le hollowboard devient rapidement un instrument essentiel de la panoplie du sauveteur en mer, comme par exemple à Santa Monica où il est adopté en $1932^{24}$. Amenés à manipuler les planches au quotidien, les sauveteurs deviennent les premiers pratiquants de ce nouveau sport.

Dans les clichés qui accompagnent l'article du National Geographic, Blake est représenté devant ses planches avec un simple short en guise de vêtement (une tenue encore considérée comme osée au début des années 1930), le torse et le dos nus. Les cheveux blondis par le soleil et laissés au naturel, la peau bronzée et le torse musclé, mais sans excès, il pose avec nonchalance. Il incarne un nouvel idéal masculin: un homme sportif mais qui n'est pas pour autant excessivement musclé (comme pouvaient l'être Eugen Sandow

23. Los Angeles Times, 14 avril 1940, H3.

24. Los Angeles Times, 29 juillet 1932, 10. 
ou Charles Atlas ${ }^{25}$, proche de la nature et des éléments et dont l'apparence n'est pas travaillée à l'excès. Blake participe ainsi à la naissance d'un nouveau modèle de masculinité fondé sur la jeunesse, l'hédonisme et la sensualité. Le sauveteur en mer, auparavant mal considéré par la population en raison du nombre de noyades, prend, avec George Freeth et Thomas Blake, une nouvelle dimension. Non seulement les équipes de sauveteurs en mer sont composées de professionnels et non plus de bénévoles à partir de la fin des années 1920 (Verge 2007, 22), mais l'image du sauveteur en mer devient celle d'un héros musclé, bronzé et décontracté. Johnny Weissmuller, le célèbre champion olympique de natation qui connaît un grand succès en incarnant le personnage de Tarzan à l'écran entre 1932 et 1948, renforce cette image quand, en 1932, il devient membre honoraire des sauveteurs en mer de SantaMonica. En 1941, le stéréotype du sauveteur en mer bronzé, blond et musclé est tellement ancré dans les imaginaires de la plage sud-californienne que dans des fiches distribuées dans la région afin de prévenir les comportements dangereux sur la plage, il est précisé qu' «il ne faut pas essayer d'obtenir un bronzage de sauveteur en mer le premier jour que l'on passe sur la plage ${ }^{26} \gg$.

En parallèle, l'ouvrage de Tom Blake joue un rôle fondamental dans l'émergence d'une communauté de surfeurs en Californie du Sud composée en grande partie de sauveteurs en mer. Ces derniers mènent un mode de vie spécifique, directement inspiré des écrits de Blake. En effet, dans Hawaiian Surfriders, Blake évoque son quotidien à Waikiki. Il refuse de se plier aux contraintes imposées par la société occidentale et choisit de vivre comme bon lui semble. Il passe ainsi sa journée sur la plage à nager, surfer et dormir au soleil. Sa tenue, un short et une paire de baskets en toile, est également le reflet de son refus des conventions sociales (Blake 40). La communauté de surfeurs qui émerge en Californie du Sud semble obéir aux mêmes préceptes. Dans les articles de presse des années 1930 consacrés au phénomène, les surfeurs semblent n'avoir qu'une idée en tête: s'amuser. Leurs horaires sont différents de ceux du reste de la sociétéet ne respectent que la logique des vagues. Même

25. Eugen Sandow et Charles Atlas sont deux artistes qui contribuent à l'émergence d'un nouvel idéal physique de masculinité à la fin du XIX ${ }^{\mathrm{e}}$ siècle. Sandow et Atlas tranchent avec l'idéal physique masculin de l'époque victorienne, c'est-à-dire l'homme svelte et élancé. Mais ils se distinguent également de l'homme fort (strongman) des foires, car ils arborent un corps à la symétrie parfaite, où chaque muscle est travaillé. Eugen Sandow, qui se produit à travers les États-Unis dans les années 1890, est aujourd'hui considéré comme l'un des pères du bodybuilding. Charles Atlas s'inspire de son exemple et se fait attribuer le titre d' «homme le plus beau du monde» en 1921. John F. Kasson, Houdini, Tarzan, and the Perfect Man: The White Male Body and the Challenge of Modernity in America (New York: Hill and Wang, 2001); David Chapman, Sandow the Magnificent. Eugen Sandow and the Beginnings of Bodybuilding (Urbana: U of Illinois P, 2006).

26. Los Angeles Times, 14 avril 1941, A3. 
dans leur pratique sportive, les surfeurs dégagent une certaine décontraction, une «nonchalance qu'ils cultivent pendant plusieurs années ${ }^{27}$ ». Dès les années 1930, les surfeurs apparaissent donc comme une communauté à part, définie par l'importance accordée au sport, à la nature et au groupe.

Toutefois, cette culture a un impact bien plus important que ne le laisserait penser le nombre restreint de surfeurs à cette époque. Hollywood s'empare ainsi rapidement du motif du surf et de la culture hawaïenne en général, comme l'illustre la vague des films des mers du Sud (South Seas Movies) des années 1930 et $1940^{28}$. Duke Kahanamoku et Tom Blake jouent eux-mêmes dans de nombreux films, bien que le premier soit souvent cantonné au rôle de chef indien ou hawaïen et le second principalement utilisé en tant que cascadeur (Booth 314). Néanmoins, les deux hommes, par leurs connaissances dans le milieu du cinéma et leurs apparitions récurrentes à l'écran, contribuent à la popularisation du sport à Hollywood. Blake joue également un rôle important dans la diffusion du sport à travers ses photographies. En 1931, il parvient ainsi à publier ses clichés dans le Los Angeles Times ${ }^{29}$. Ces photographies et ces films circulent et influencent progressivement les cultures et les usages de la plage, au-delà de la communauté des surfeurs. En effet, au début du siècle, l'exotisme des régions tropicales, tel qu'il est approprié et réinventé par les industries du tourisme et de la publicité, connaît un grand succès auprès des classes moyennes et supérieures américaines. Dans un contexte d'expansion des échanges commerciaux et des circuits touristiques entre les États-Unis et Hawaï, les produits culturels issus des tropiques ne sont plus seulement perçus comme une menace pour l'homme blanc civilisé des zones tempérées, comme c'est le cas pendant l'ensemble des XVIII et XIX ${ }^{\mathrm{e}}$ siècles, mais au contraire comme un moyen de se régénérer, de redécouvrir son corps et sa sensualité, tout du moins le temps de l'été ou d'une soirée (Cocks). La mode du luau, une fête organisée sur le sable accompagnée de musique, se répand ainsi en Californie dès les années 1910, en parallèle à la diffusion du surf. Dans les années 1920, le ukulélé et les mandolines font partie intégrante des fêtes de plage. Les motifs hawaïens sont également utilisés dans la décoration des maisons de plage des élites et dans les soirées mondaines organisées par les clubs de plage privés. Une fois importés sur les plages de Los Angeles, ces éléments permettent de conférer au club une atmosphère exotique et primitive prisée des Angelinos. Ces emprunts ne sont pas uniquement le fait des Angelinos blancs. Le club composé de jeunes femmes noires, «les bonnes amies», organise par exemple en 1925 une fête

27. Los Angeles Times, 19 septembre 1937, J6

28. Sur ce sujet, voir Robert C. Schmitt, «South Seas Movies, 1913-1943». Hawaii Historical Review 2.11 (1968) : 433-452.

29. Los Angeles Times, 24 mai 1931, H3. 
de plage au cours de laquelle on danse au son du ukulélée ${ }^{30}$. Toutefois, il est certain que pour les Blancs l'attrait des exportations polynésiennes tient pour beaucoup à la racialisation des corps indigènes sur lesquels on projette une sensualité exacerbée. Après la guerre, cette culture du luau et le mode de vie $\mathrm{du}$ «beach bum» deviendront un phénomène beaucoup plus important et, surtout, moins consensuel. À la faveur de la diffusion du sport parmi la jeunesse californienne dans les années 1960, le surf est en effet progressivement associé au monde de la délinquance juvénile et de la drogue.

À la fin des années 1930, les symboles incontournables de la plage sudcaliforniennes sont donc en place. Contrairement à ce que l'on aurait pu croire, les figures de la starlette en maillot de bain (ou bathing beauty), du bodybuilder et du surfeur datent de bien avant l'après-guerre. Prendre en compte la genèse de ces «types» corporels met en valeur l'histoire spécifique de Los Angeles, ville champignon dont l'incroyable croissance démographique au début du $\mathrm{XX}^{\mathrm{e}}$ siècle tient en grande partie au développement de l'économie du tourisme et de l'industrie cinématographique. Surtout, cette profondeur de champ historique fait apparaître le rôle syncrétique que jouent les plages de Los Angeles au début du siècle. Situées à mi-chemin entre la ville et le balnéaire, elles constituent un lieu d'expérimentation, où les influences croisées de Hollywood, du culte du corps développé dans les clubs de sport du centre-ville et des importations hawaïennes donnent naissance à des cultures corporelles originales. Bien entendu, ces usages et cultures de plage vont connaître des transformations et, surtout, une diffusion plus large dans les années 1950 et 1960. Néanmoins, les grandes lignes sont là: contrairement aux rivages européens, les plages californiennes se libèrent rapidement des préoccupations médicales et hygiénistes pour laisser toute sa place à la recherche du plaisir et la quête de la beauté corporelle. En même temps, la présence d'une ville en pleine explosion démographique à quelques pas de la plage contribue à imposer la Californie du Sud comme un lieu d'innovation et de diffusion des nouvelles modes balnéaires. Grâce au formidable pouvoir de résonance de Los Angeles (par le biais des journaux, de la radio, des films, des migrations, du bouche à oreille, etc.), ces innovations voyageront vite et loin. Au lendemain de la guerre, et surtout dans les années 1960, les plages mondiales se mettront au diapason de Los Angeles.

30. California Eagle, 7 août 1925, 4 


\section{OUVRAGES ET ARTICLES CITÉS}

AdDison, Heather. Hollywood and the Rise of Physical Culture. Londres : Routledge, 2003.

BANNER, Lois. American Beauty: A Social History through Two Centuries of the American Idea, Ideal, and Image of the Beautiful Woman. New York: Alfred \& Knopf, 1983.

Basinger, Jeanine. Silent Stars. Hanover, NH: Wesleyan UP, 2000.

BLAKE, Tom. Hawaiian Surfriders. Redondo Beach: Mountain \& Sea, 1998.

—. «Waves and Thrills at Waikiki». National Geographic 67 (1935): 597-604.

Воотн, Douglas. «Surfing Films and Videos: Adolescent Fun, Alternative Lifestyle, Adventure Industry ». Journal of Sport History 23.3 (1996) : 313-327.

-. Australian Beach Cultures: The History of Sun, Sand and Surf. Londres: Routledge, 2012.

Cocks, Catherine, Tropical Whites: The Rise of the Tourist South in the Americas. Philadelphie: U of Pennsylvania P, 2013.

Culver, Lawrence. The Frontier of Leisure: Southern California and the Shaping of Modern America. New York: Oxford UP, 2010.

D'HAeYere, Hilde. "Splashes of Fun and Beauty. Mack Sennett's Bathing Beauties ». Slapstick Comedy. Londres: Taylor \& Francis, 2009. 207-255.

Diamond, Andrew. «Surfin' Usa: California Surf Culture, Whiteness, and the Undercurrents of the Great Society Backlash». Annick Foucrier et Antoine CoPPOLANI, eds., La Californie : Périphérie ou Laboratoire ? Paris: L'Harmattan, 2004.

LAWLer, Kristin. The American Surfer: Radical Culture and Capitalism. Londres: Taylor \& Francis, 2011.

Lynch, Gary, Malcolm Gault-Williams, et William K. Hoopes. Tom Blake: The Uncommon Journey of a Pioneer Waterman. Limited ed. Croul Family Foundation, 2001.

MAY, Kirse Granat. Golden State, Golden Youth: The California Image in Popular Culture, 1955-1966. Chapel Hill: U of North Carolina P, 2002.

McWilliams, Carey. Southern California: An Island on the Land. Santa Barbara: Peregrine Smith, 1973.

RAINIS, Michel. «French Beach Sports Culture in the Twentieth Century». International Journal of the History of Sport 17.1 (2000) : 144-158.

- Histoire des clubs de plage au $\mathrm{XX}^{e}$ siècle : exercices, jeux, concours et sports sur le sable. Paris: L'Harmattan, 2001.

Rose, Marla Matzer. Muscle Beach. New York: St. Martin's Griffin, 2001.

Verge, Arthur C. "George Freeth: King of the Surfers and California's Forgotten Hero». California History 80 (2001): 82-105.

Warshaw, Matt. The History of Surfing. San Francisco: Chronicle Books, 2010.

ZINKIN, Harold et Bonnie Hearn. Remembering Muscle Beach: Where Hard Bodies Began: Photographs and Memories. Santa Monica: Angel City Press, 1999. 